\title{
Importance of best Human Resource Management Practices and the need for a Human Resource Information System (HRIS) for the Public Health Sector in Sri Lanka
}

\author{
Dr. L. M. Mujeeb BDS, MSc \\ Medical Officer, MBBS, Health Informatics, Ministry of Health, Colombo, Sri Lanka \\ E-Mail address: immujeeb73@gmail.com
}

Sri Lanka Journal of Bio-Medical Informatics 2012;3(2):-55-62

doi: http://dx.doi.org/10.4038/sljbmi.v3i2.2449

\begin{abstract}
Human Resource (HR) management practices are essential for delivering effective healthcare services in hospitals. To maximise the usage of available HR, an effective and prudent HR management policy is essential. Special emphasis is necessary with regard to the HR management of public sector doctors and dental surgeons. A Health Resource Information System (HRIS) is helpful in achieving this. Such a system should be sustainable and affordable.
\end{abstract}

Keywords - Healthcare; Human Resources Development Plans (HRDP); HR management, organisational management; personal management; personnel administration; Resource Requirements Tool (RRT); training and development; workforce planning

\section{Introduction}

Human Resource Management (HRM) is the strategic and coherent approach to the management of an organisation's most valued assert, i.e. the people working there who individually and collectively contribute to the achievement of the objectives of the business $^{(1,2)}$. The terms 'Human Resource Management' and 'Human Resources' (HR) have largely replaced the term 'personnel management' as a description of the processes involved in managing people in organisations ${ }^{(1,2)}$. In simple words, Human Resource Management means employing people, developing their capacities, and utilising, maintaining and compensating their services in tune with the job and organisational requirements.

The same is applicable to the health sector as well. In Sri Lanka, the public health sector which is under the Ministry of Health is the main healthcare provider. The public health sector in Sri Lanka is the second largest public service provider next to education. As of 31 December 2009, the Sri Lankan public health sector employed a total of 13,734 medical doctors in all grades and categories and 1,022 dental surgeons in all grades and categories ${ }^{(3)}$. Sri Lanka has 3.6 hospital beds per 1,000 patients and 2,300 patients are looked after by a doctor, while around 25,000 patients are looked after by a single dental surgeon and 12 nurses look after 10,000 patients $^{(4)}$. Organising these personnel who form the nucleus of the health care delivery is a huge task. To ensure an even delivery of the services in a country which suffered a war for three decades, the Ministry of Health should devise a plan which would ensure that healthcare services reach each citizen of Sri Lanka.

\section{Attempts towards best HRM standards in Sri Lanka in the past}

There have been several initiatives to develop a method for better management of human resources in the public health sector in the past. In the 1960s, a task force was set up by the 
Ministry of Health to design a national health plan, including managing human resources in the sector ${ }^{(4)}$. In 1975, a health manpower study was undertaken. In the late 1970s and early 1980s, two studies, one on cadre determination of all medical, nursing and paramedical personnel (Report of staffing study 1981) and the other on nursing (1977) were undertaken ${ }^{(4)}$. In 1992, a National Health Policy was initiated. In 1993, a study was undertaken by the Human Resource Development Council on Human Resource Development in the health sector. In 1994, a perspective plan for Health Development in Sri Lanka was formulated from 1995 to 2004. Their impact on policy and the plan of Human Resource Development are unknown $^{(4)}$. In 1993, a study found that health manpower planning in Sri Lanka has been episodic and to a large extent limited in scope; health manpower development in the private sector has not been given due consideration and the demand pattern for services and technological changes have not been taken into account ${ }^{(4)}$. In addition there have been some studies that examined issues of HR policy and management in the public sector health system, such as the draft Strategic Human Resource Plan 1999-2009 and the Health Manpower Development Plan for Sri Lanka 1997-2006. The Health Manpower Development Plan (1997-2006) precisely describes what should be done with regard to Human Resource Development (HRD) policy formulation and plan formulation, production, manpower management etc. However, none of them have been implemented so $\operatorname{far}^{(4)}$.

\section{Present situation of HRM in the Sri Lankan public health sector}

One of the big issues in HRM in the public health sector in Sri Lanka is that there is no overall HR policy and development plan ${ }^{(4)}$. This is due to lack of organisation at national level $^{(4)}$. The absence of a central HR unit or department or that of a durable mechanism to link functions of several units within the Ministry of Health might serve as a handicap leading to lack of coordination and poor decision making ${ }^{(4)}$.

Although computers are used in order to assist, HR record keeping is manually done. HRM is run in isolation. For example, the system in the Kurunegala teaching hospital does not communicate to the Central or Provincial Health Authority departments. Transferring data from one section to another section within the Ministry itself or from one healthcare institution to another is an arduous and time consuming task. When healthcare personnel are transferred from one healthcare institution to another, data and documents do not transfer swiftly.

Withanachchi et al. (2007) observe that allocative inefficiency is a fundamental flaw in public hospitals in developing countries ${ }^{(5)}$. The inefficiencies drain the limited public resources allotted for healthcare. Sri Lanka's public health system faces worsening budget constraints $^{(5)}$. The resource allocation practices of the Ministry of Health focus on increasing the hospital staff, consequently crowding out the investments on facility development ${ }^{(5)}$. The results suggest that the human resource utilisation is suboptimal due to the inadequacy of capital investment. The re-orientation of resource allocation towards capital investments may save more lives ${ }^{(5)}$.

\section{Some related work previously done}

For a HRM system to be successful, it should include 'organisational management', 'personnel administration', 'manpower management and 'industrial management' ${ }^{(6)}$. But these traditional expressions are becoming less common for the theoretical discipline. 
Sometimes even employee and industrial relations are confusingly listed as synonyms, although these normally refer to the relationship between management and workers and the behaviour of workers in companies.

HRM techniques, when properly practiced, express the goals and operating practices of the enterprise overall. This is true for the healthcare systems as well. HRM is also seen by many to have a key role in risk reduction within organisations ${ }^{(7)}$.

HRM in healthcare involves several processes. When effectively integrated they provide significant economic benefit to the Healthcare organisations ${ }^{(8)}$. Workforce planning, recruitment (sometimes separated into attraction and selection), induction, orientation and onboarding, skills management, training and development, personnel administration, compensation, time management, travel management, payroll (sometimes assigned to accounting) employee benefits administration, personnel cost planning, performance appraisal and good labour relations are all part of $\mathrm{HRM}^{(8)}$.

Martineau et al. (2008) highlight the importance for low income countries to develop a clear strategy to develop their health workforce, including a projection of costs over a multi - year period $^{(9)}$. A 'costed' plan is credited by helping to identify financing gaps and serving as an advocacy tool in the process of mobilising resources.

The approach to planning and costing Human Resources Development Plans (HRDP) in the health sector involves four steps ${ }^{(10)}$ :

1. Estimating the number of required additional staff.

2. Multiplying those numbers by current and future public sector salaries and allowances.

3. Calculating financial needs on the basis of projected funds and

4. Discussing financing options.

However, this rational approach does not take into account the dynamics of the labour market, and often ignores healthcare personnel's propensity to emigrate ${ }^{(10)}$.

Bloor and Maynard consider that it is important to factor in the supply and demand of health personnel in the public and private healthcare sectors ${ }^{(11)}$. Rutten argues that human resource for health planning should adopt general equilibrium models bringing together labour market factors and fund availability ${ }^{(12)}$.

The World Health Organisation (WHO) has recognised the importance of this issue and has launched initiatives such as the Working Group on Tools and Guidelines to strengthen the analysis of the costs of HR for health development ${ }^{(13)}$. The Global Health Workforce Alliance (GHWA) supported the development of a Resource Requirements Tool (RRT) to help local governments estimate the costs of HR for health plans and policies ${ }^{(14)}$.

The RRT provides a methodology to collect information on HR and the local economy. HR requirements helps calculate and project the costs of different HR for health training and recruitment options to local governments ${ }^{(15)}$. The tool calculates salary and incentives (financial as well as the monetary value of non-financial incentives, such as free meals, transport and accommodation) training, capital and equipment expenses and compares them 
with the projected funds. The concept of 'fiscal space' i.e. a country's ability to find the financial resources required to finance the anticipated spending ${ }^{(16)}$ is evaluated by taking into account the country's expected economic growth, the current level of GDP, the share of government resources allocated to health and the share allocated to personnel expenses ${ }^{(17)}$.

Recent work shows that many national HR for health strategies fail to include a comprehensive review of costs. This is the case for Eritrea, Rwanda, Sierra Leone, Zambia, South Africa and Sudan ${ }^{(18)}$.

Stefane et al. (2006) found that the relationship between HRM and healthcare is extremely complex, particularly when examined from a global perspective ${ }^{(19)}$. It has been done in Canada, United States of America, Germany, Ghana, Kenya, South Africa and Zimbabwe. Several key questions must be addressed and HRM must play an essential role in health care sector reforms ${ }^{(19)}$. They found a surplus of physicians in Germany causing problems. On the other hand, migration of health workers to more affluent regions and/or countries was also causing problems ${ }^{(19)}$. A strong understanding of the HRM issues is required to ensure the success of any health care programme ${ }^{(19)}$.

Decentralising recruitment from central Government to the respective district administration was shown to be effective in strengthening public health sector ${ }^{(19)}$.

It was shown that the aid effectiveness agenda offers solutions to both multisectoral nature of HR for healthcare issues as well as to ineffective donor behaviour. Researchers demonstrated how this policy instrument promotes an integrated, holistic response to a range of such complex challenges ${ }^{(21)}$.

A study recommends adopting of a systematic sharing of experiences across and within the countries in planning and implementing different types of HR in healthcare data collection. This system should be routine and periodic in nature, in order to build a global knowledge base on lessons learnt and best practices in information generation to support evidence based decision making ${ }^{(21)}$.

Although priority attributed to HR in healthcare is increasing, there is still a focus on single initiatives and programmes. This is partly due to the complexity of the issue and partly due to its need to be addressed through a long term approach that go beyond the health sector ${ }^{(23)}$. Enabling country ownership, inter-sectoral and sustainable system approaches are required to effectively address HR in healthcare when global partners are involved ${ }^{(23)}$. Since many areas of HR in healthcare are perceived as government terrain, the countries concerned need to take a lead in defining priorities and targets that may be technically supported by global partners $^{(23)}$.

The success in the Sultanate of Oman on health workforce development planning was because the workforce plans matched well with the health plans and it had the full support of the top management. They made sincere efforts to collaborate with all relevant departments and institutions ${ }^{(24)}$. The methodology used by the planners was objective and transparent, ie. clearly elucidated and open for discussion and further development. The information used for planning was fairly accurate and reliable, thanks to a well-functioning health information system $^{(24)}$. 
To run a sustainable and successful Human Resources Information Systems (HRIS), implementation of a retention strategy of technical staff, improvement of monitoring and evaluation systems, strategically plan early success stories for demonstration and support for Open Source ICT developers networks and education are necessary ${ }^{(25)}$.

Largrade et al. (2009) say that discreet choice experiments could be a particularly valuable method in the field of HR research in developing countries where reliable retrospective datasets are scarce and prospective studies are needed to support decisions ${ }^{(26)}$ and help reduce public, private and rural-urban maldistribution ${ }^{(26)}$. Although some software programmes now provide tools to help researchers construct optimal designs, a proper experimental design is evolving and might limit the use of discreet choice experiment methods ${ }^{(26)}$. Although experiments may be useful in informing decision making in developing countries, HR researchers should be aware of the technical expertise required to use them, as well as their possible limitations ${ }^{(26)}$.

Another recent study in nine countries found that health systems suffer from poor human resource management, resulting in the absence of effective recruitment and retention strategies, poor HR planning, lack of proper performance evaluation mechanisms and absence of a policy for re-licensing of medical staff and other negative consequences. HRM challenges in healthcare organisations should be valued by policy makers and managers and developing effective HR strategies should become a priority ${ }^{(27)}$.

HRM is a discipline which requires a distinct knowledge base and training. There is a need to expand knowledge on HR and competencies for the effective management of $\mathrm{HR}$ in healthcare organisations. There is also a need to increase the pool of competent HR professionals. A new cadre of HR managers will need to be trained and enabled to have real input into operational and strategic decisions about $\mathrm{HRM}^{(28)}$.

\section{Conclusion}

The public healthcare system is the main player in delivering healthcare services in Sri Lanka. It is important to maximise the usage of available healthcare personnel in the public sector by managing them properly. Best HRM practices are essential to meet this goal. A HRIS is an immensely helpful tool in best HRM practices. Such a system should be effectively running, economically feasible and sustainable in the long run. Designing a health resource information system requires proper planning. Many systems have failed in spite of spending colossal amounts of money without proper planning. Failure in change management is another reason for such failures. Although the use of discreet choice experiments methods exist, proper experimental design is evolving. As HRM is a professional skill, those nonprofessional managers like heads of public healthcare institutions need proper training and best practices. Finding donors is an issue. Other issues are; enabling country ownership, intersectoral and sustainable system approaches. These are needed to effectively address human resources in healthcare when global partners are involved. To run a sustainable and successful HRIS, implementation of retention strategy of technical staff, improvement of monitoring and evaluating systems, strategic plan of early success stories, Open Source ICT developers networks and education are necessary. 


\section{References}

1. Wikipedia. Available on: http://en.wikipedia.org/wiki/Human_resource_management. Accessed on 14 September 2010.

2. Michael A, 2006. A Handbook of Human Resource Management Practice. 10th ed. Kogan Page. ISBN 0-7494-4631-5. OCLC 62282248.

3. Ministry of Health official web site. http://www.health.gov.lk/. Accessed on 27 September 2010.

4. Samarage S. Migration and Human Resources for Health: From Awareness to Action. Development, Ministry of Health, Sri Lanka. 2006

5. Withanachchi N, Uchida Y, Nanayakkara S, Samaranayake D, Okitsu A. Resource allocation in public hospitals: Is it effective? Health Policy Journal 2007; 80(2): 308-13. doi: http://dx.doi.org/ 10.1016/j.healthpol.2006.03.014

6. Personnel management. The Columbia Encyclopedia (Sixth Edition). Columbia University Press. 2005.

7. Towers, D. Human Resource Management Essays. http://www.towers.fr/essays/hrm.html. Accessed on 27 September 2010.

8. Flynn WJ, Jackson JH, Langan PJ, Mathis RL Healthcare Human Resource Management, Second Edition. ISBN: 0324317042 Thomson South-Western March 2006.

9. Martineau T, Caffrey L. Human Resources for Health Strategic Planning. In Capacity Project Technical Brief No. 92008 Chapel Hill NC: Capacity Project; 2008.

10. Glassman A, de Ferranti D, Becker L, Makinen M: Planning and costing human resources for health. Lancet 2008; 371: 693-695.

doi: http://dx.doi.org/10.1016/S0140-6736(08)60311-6

11. Bloor K, Maynard A: Planning human resources in health care: Towards an economic approach. An international comparative review. In Canadian Health Services Research Foundation Ottawa, Ontario; March 2003.

12. Rutten M: Towards a comprehensive economic methodology for estimating the cost of human resources for health under alternative scenarios. In KIT Working Papers Series H2 Amsterdam: KIT 2008.

13. WHO. New Task Force Launched to Address Human Resources Financing. 2008. http://www.who.int/mediacentre/news/notes/2008/np02/en/index.html 
14. GHWA: Financing and economic aspects of health workforce scale-up and improvement: framework paper. In Task Force on Human Resources for Health Financing. Global Health Workforce Alliance. Geneva. 2009

15. GHWA: Herramienta de requerimento de recursos humanos para la salud. In Versión 1.1. Task Force on Human Resources for Health Financing. Global Health Workforce Alliance. Geneva. 2009.

16. Heller PS: The prospect of creating 'fiscal space' for the health sector. Health Policy and Planning 2006; 21(2):75-79. doi: http://dx.doi.org/10.1093/heapol/czj013

17. GHWA: Data collection guide for the RRT. In Task Force on Human Resources for Health Financing. Global Health Workforce Alliance. Geneva. 2009.

18. Vujicic M, Ohiri K, Sparkes S. Working in Health: Financing and Managing the Public Sector Health Workforce. Washington D.C. The World Bank, 2009. http://go.worldbank.org/PU86PVIEU0

19. Stefane M Kabene, Carole Orchard, John M Howard, Mark A Sorianoland Raymond Leduc1. Research The importance of human resources management in health care: a global context. Human Resources for Health 2006; 4: 20 doi: http://dx.doi.org/10.1186/1478-4491-4-20.

20. Heywood PF, Harahap NP. Research Human resources for health at the district level in Indonesia: the smoke and mirrors of decentralization. Human Resources for Health 2009; 7: 6 doi: http://dx.doi.org/10.1186/1478-4491-7-6

21. Rebecca Dodd, Peter S Hill, Dean Shuey and Adélio Fernandes. Research Paris on the Mekong: using the aid effectiveness agenda to support human resources for health in the Lao People's Democratic Republic. Human Resources for Health 2009; 7:16. doi: http://dx.doi.org/10.1186/1478-4491-7-16

22. Gupta N, Dal Poz MR. Research Assessment of human resources for health using crossnational comparison of facility surveys in six countries. Human Resources for Health 2009; 7: 22. doi: http://dx.doi.org/10.1186/1478-4491-7-22

23. Windisch R, Wyss K, Prytherch H. Research A cross-country review of strategies of the German development cooperation to strengthen human resources. Human Resources for Health. 2009; 7: 46.

doi: http://dx.doi.org/10.1186/1478-4491-7-46 
24. Ghosh B. Case study Health workforce development planning in the Sultanate of Oman: a case study. Human Resources for Health 2009; 7.

doi: http://dx.doi.org/10.1186/1478-4491-7-47

25. De Vries DH. Evaluation of the Capacity Project's Human Resources Information Systems (HRIS) Strengthening Process in Swaziland, Uganda and Rwanda July 2009. Intra Health International/The Capacity Project George Blair, Consultant Kairie Morgan, Consultant. USAIDS/ The Capacity Project.

26. Lagarde M, Blaauw D. Review A review of the application and contribution of discrete choice experiments to inform human resources policy interventions. Human Resources for Health 2009; 7: 62

doi: http://dx.doi.org/10.1186/1478-4491-7-62

27. El-Jardali F, Makhoul J, Jamal D, Tchaghchaghian V. Identification of Priority Research Questions Related to Health Financing, Human Resources for Health, and the Role of the Non-State Sector in Low and Middle Income Countries of the Middle East and North Africa Region. Research Report Submitted to Alliance for Health Policy and Systems Research. 2008.

28. El-Jardali F, Tchaghchagian V, Jamal D. Research Assessment of human resources management practices in Lebanese hospitals. Human Resources for Health 2009; 7: 84. doi: http://dx.doi.org/10.1186/1478-4491-7-84 